\title{
New Insights for Diagnosis of Pineapple Fusariosis by MALDI-TOF MS Technique
}

\author{
Cledir Santos $^{1} \cdot$ José Aires Ventura $^{2} \cdot$ Nelson Lima ${ }^{3}$
}

Received: 27 August 2015/ Accepted: 7 April 2016/Published online: 27 April 2016

(C) Springer Science+Business Media New York 2016

\begin{abstract}
Fusarium is one of the most economically important fungal genus, since it includes many pathogenic species which cause a wide range of plant diseases. Morphological or molecular biology identification of Fusarium species is a limiting step in the fast diagnosis and treatment of plant disease caused by these fungi. Mass spectrometry by matrix-assisted laser/desorption ionisation-time-offlight (MALDI-TOF)-based fingerprinting approach was applied to the fungal growth monitoring and direct detection of strain Fusarium guttiforme E-480 inoculated in both pineapple cultivars Pérola and Imperial side shoots, that are susceptible and resistant, respectively, to this fungal strain. MALDI-TOF MS technique was capable to detect fungal molecular mass peaks in the susceptible pineapple stem side shoot tissue. It is assumed that these molecular masses are mainly constituted by ribosomal proteins. MALDITOF-based fingerprinting approach has herein been demonstrated to be sensitive and accurate for the direct detection of $F$. guttiforme E-480 molecular masses on both susceptible and resistant pineapple side stem free of any pre-treatment. According to the results obtained, the changing on molecular mass peaks of infected susceptible pineapple tissue together with the possibility of fungal
\end{abstract}

Cledir Santos

cledir.santos@ufrontera.cl

1 Department of Chemical Sciences and Natural Resources, CIBAMA, BIOREN-UFRO, Faculty of Engineering and Science, Universidad de La Frontera, Av. Francisco Salazar 01145, 4811-230 Temuco, Chile

2 Instituto Capixaba de Pesquisa, Assistência Técnica e Extensão Rural, INCAPER, Vitória, ES, Brazil

3 CEB-Centre of Biological Engineering, Micoteca da Universidade do Minho, University of Minho, 4710-057 Braga, Portugal molecular masses analysis into this pineapple tissue can be a good indication for an early diagnosis by MALDI-TOF MS of pineapple fusariosis.

\section{Introduction}

Fusarium is one of the most economically important fungal genera comprising more than 1000 species and including many pathogenic species which cause a wide range of plant diseases. Morphological identification is a limiting step in the knowledge and treatment of plant disease caused by Fusarium.

Although morphological observations for Fusarium genus may not be enough for complete identification at species level, a great deal of information is usually obtained on the culture at this stage [19]. In addition, it has had a confusing and unstable taxonomic history [7]. It is due to the various classifications that are being used, including subgenus and subspecies categories such as sections and formae speciales. Moreover, the duality between teleomorph and anamorph taxonomies and conventional identification based on morphological traits is hindered by major phenotypic polymorphism [12] .

Matrix-assisted laser desorption/ionisation time-of-flight (MALDI-TOF) is a technique of mass spectrometry that has demonstrated high potentiality on the identification of filamentous fungi at species and, in some specific cases, at strain level [20]. One of the most interesting advantages of the technique is the possibility of analysing the intact fungal cell generating specific molecular mass profiles [16$18,20,22,26]$.

As previously described elsewhere $[16,17,26]$, these specific molecular masses are mainly constituted by ribosomal proteins. When applied to the fungal identification, 
the remarkable reproducibility of MALDI-TOF MS technique is based on the measurement of these highly abundant organic chemical compounds, which are observed on the mass spectra as very specific mass peaks.

The mass peaks generated by the analysis of these ribosomal proteins are observed in a mass range between 2 and $20 \mathrm{kDa}$. Also, compounds such as polysaccharides, lipids, phospholipids, chitin, and among others can similarly be found in the fungal cell. All of these are very useful in fungal identifications by mass spectrometry $[9,13,17$, 18, 20, 22].

Studies have demonstrated the high potentiality of the technique for species and strain identification within Fusarium genus [2, 4, 5, 9]. Furthermore, in a previous study, Santos et al. [23] used the pineapple Pérola cultivar as standard for susceptibility to the plant pathogen Fusarium guttiforme. The authors used MALDI-TOF MS to establish a multistep identification of this plant pathogen (F. guttiforme) and its antagonist Trichoderma asperellum. However, the monitoring of $F$. guttiforme growth into the pineapple side shoots using both susceptible and resistant pineapple cultivars is missing in the literature.

The aim of the present work is to evaluate the capability of MALDI-TOF to detect specific mass peaks, such as ribosomal proteins, of strain $F$. guttiforme E-480, without any previous treatment, into both resistant and susceptible pineapple cultivars side shoot's cellular wall.

\section{Materials and Methods}

\section{Microbial Strains}

Strain F. guttiforme E-480 was obtained from the INCAPER Culture Collection (INCAPER, http://www.incaper. es.gov.br/). Escherichia coli strain DH5 $\alpha$ was obtained from the Micoteca da Universidade do Minho Culture Collection (MUM, www.micoteca.deb.uminho.pt). Both fungal and bacterial strains were obtained from preserved cultures at $-80{ }^{\circ} \mathrm{C}$. Cryovials were thawed, opened and the strains sub-cultured according to the instructions issued by INCAPER and MUM.

\section{Pineapple Infection}

Imperial and Pérola cultivars, which are resistant and susceptible, respectively, to the strain $F$. guttiforme E-480, were used.

A 5-mm diameter hole was made in the resistant and susceptible pineapple side shoots by means of a drill. A $100 \mu \mathrm{l}$ suspension of $F$. guttiforme E-480 in water containing $10^{4}$ conidia $\mathrm{ml}^{-1}$ was dispensed into the hole.
The infected pineapple side stems were placed into a sterile plastic bag and incubated at $25{ }^{\circ} \mathrm{C}$ during 5 days on the dark without humidity control.

\section{MALDI-TOF Analysis}

For the spectral analysis of strain $F$. guttiforme E-480, about $10^{4}$ conidia on a suspension of $0.2 \%$ agar were inoculated on 9-cm plates containing Potato Dextrose Agar (PDA, Oxoid). The plates were incubated aerobically in a dark incubator for 3 days at $25^{\circ} \mathrm{C}$. Escherichia coli DH5 $\alpha$ was grown aerobically at $37^{\circ} \mathrm{C}$ for $20 \mathrm{~h}$ and maintained on Luria-Bertani agar medium (LB: $10 \mathrm{~g} \mathrm{l}^{-1}$ bacto-tryptone, $5 \mathrm{~g} \mathrm{l}^{-1}$ bacto-yeast extract, $10 \mathrm{~g} \mathrm{l}^{-1} \mathrm{NaCl} .15 \mathrm{~g} \mathrm{l}^{-1}$ agar). Both fungal and bacterial cultures were checked for purity prior to use and were sub-cultured at least once prior to the analysis.

Approximately, $1 \mu \mathrm{g}$ of young mycelium and conidia mixture of $F$. guttiforme E-480 were transferred directly from the culture plate to the 48-well flex target plate (FlexiMass $^{\mathrm{TM}}$, Shimadzu Biotech, UK). Immediately, $0.5 \mu \mathrm{l}$ matrix solution $\left[75 \mathrm{mg} \mathrm{ml}^{-1}\right.$ 2,5-dihydroxybenzoic acid (DHB) in ethanol/water/acetonitrile (1:1:1) with $0.03 \%$ trifluoroacetic acid (TFA)] was added and mixed gently.

Using a 1-ml disposable pipet tip, a 3-mm-diameter hole was manually performed on the boundaries of the infection hole on the resistant and on the infected tissue of the susceptible pineapple side stems. The same procedure was followed on the healthy tissue of both resistant and susceptible pineapple side stems. In order to obtain an aqueous suspension on each holes, $100 \mu \mathrm{l}$ distilled and sterilised water was added and gently mixed. Then, $0.2 \mu$ l aqueous suspension was transferred from each pineapple side stem holes to the 48-well flex target plate, and $0.8 \mu \mathrm{l} \mathrm{DHB}$ matrix solution was added and gently mixed.

For E. coli DH5 $\alpha$, an approximately $1 \mu \mathrm{g}$ of cells $\left(\approx 10^{6}\right.$ cells) was directly transferred from a single colony and spotted onto the 48-well flex target plate, and then the matrix solution was added and gently mixed. Samples were air dried at room temperature. Each sample was spotted in quadruplicate to test reproducibility.

During the analyses, DHB solution was prepared and stored at $5{ }^{\circ} \mathrm{C}$. The analyses were performed on an Axima LNR system (Kratos Analytical, Shimadzu, UK) equipped with a nitrogen laser $(337 \mathrm{~nm})$, where the laser intensity was set just above the threshold for ion production. Twelve defined ribosomal proteins of intact $E$. coli DH5 $\alpha$ cells (4365.4, 5096.8, 5381.4, 6241.4, 6255.4, 6316.2, 6411.6, 6856.1, 7158.8, 7274.5, 7872.1, 9742 and 12,227.3 Da) were used as external calibrants. The mass range from 2 to $20 \mathrm{kDa}$ was recorded using the linear mode with a delay of $104 \mathrm{~ns}$ and an acceleration voltage of $+20 \mathrm{kV}$. Final 
Fig. 1 Phylogenetic analysis of tef-1 for Fusarium guttiforme strain E-480. All reference strains of Fusarium guttiforme were grouped with strain E-480 forming a single clade $(65 \%$ bootstrap) distinct from Fusarium ananatum, which is other pineapple Fusarium pathogenic species

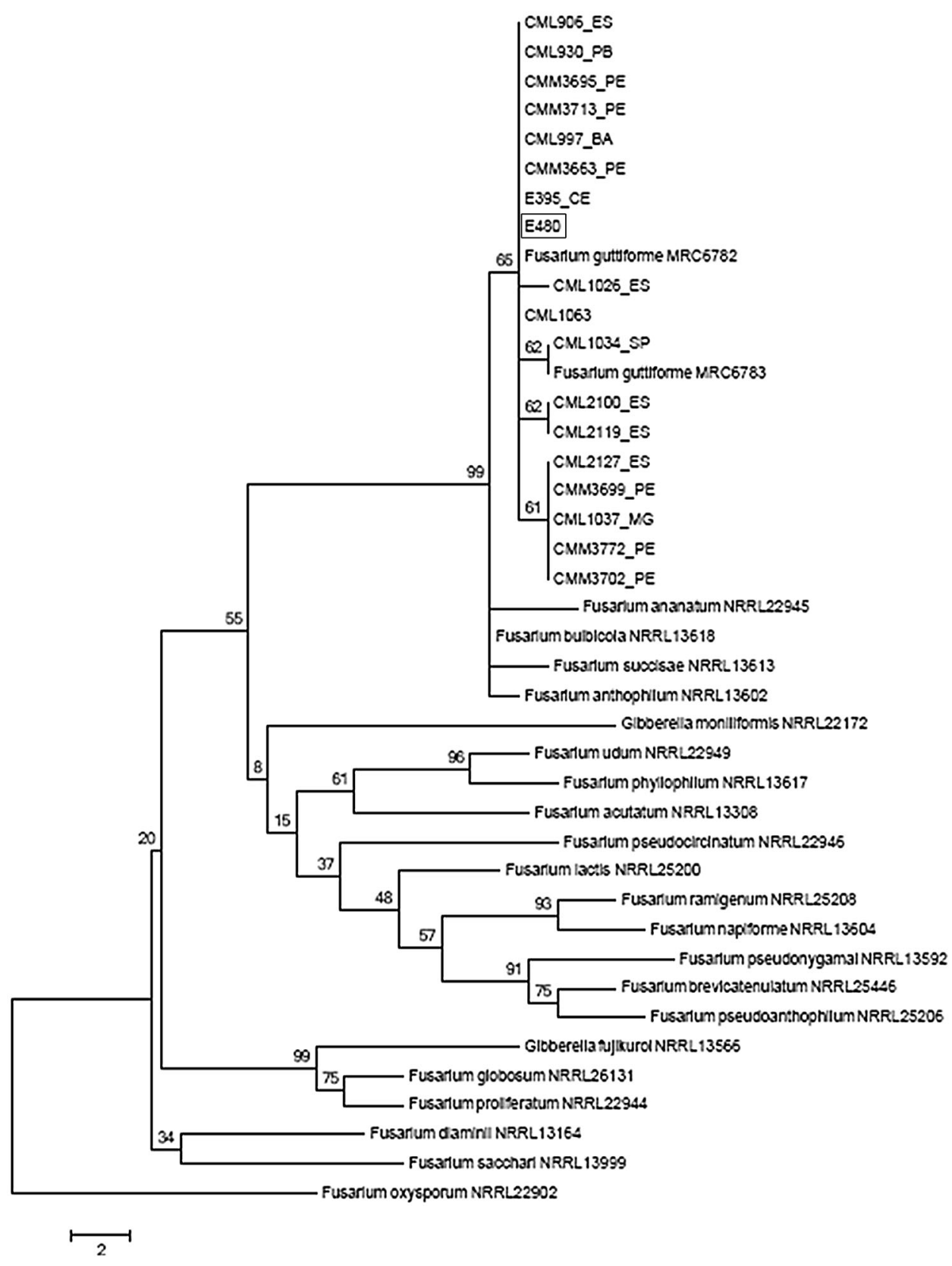

spectra were generated by summing 20 laser shots accumulated per profile and 50 profiles produced per sample, leading to 1000 laser shots per summed spectrum.

\section{Molecular Biology Analysis}

Strain $F$. guttiforme E-480 was grown in complete medium (CM: saccharose $30 \mathrm{~g} \cdot \mathrm{l}^{-1}, \mathrm{Na}_{2} \mathrm{NO}_{3} 2 \mathrm{~g} \cdot \mathrm{l}^{-1}$, protein hydrolysate $\mathrm{N}$-Z-amine $2.5 \mathrm{~g} \cdot \mathrm{l}^{-1}$, yeast extract $\mathrm{g} \cdot \mathrm{l}^{-1}$ and vitamin stock solution $10 \mathrm{ml} \cdot \mathrm{l}^{-1}$ ) at $100 \mathrm{rpm}$ in a rotary shaker at room temperature under 12:12 h light:dark conditions for 2 days, as previously described by Leslie et al.
[10]. After incubation, the fungal biomass was filtered and the excess water was removed. Cellular material was grounded to a powder with liquid nitrogen using a mortar and a pestle.

The DNA was extracted with a standard protocol based on the cetyl trimethyl ammonium bromide (CTAB) technique [10]. Partial of the translocation elongation factor $1-\alpha$ (tef-1) and $\beta$-tubulin (tub-2) genes was amplified by PCR using the primers and amplification conditions of O'Donnell et al. [15] and then sequenced. The sequences obtained were aligned with reference sequences from GenBank of Fusarium species belonging to the Gibberella fujikuroi 
Fig. 2 Pineapple side stems 5 days after inoculation with strain $F$. guttiforme E-480. a resistant cultivar and b susceptible pineapple cultivar to strain $F$. guttiforme E-480. Arrows indicate the area of sample collection for MALDI analysis of healthy tissue (a) and lesion board (b) of resistant pineapple, and healthy tissue $(c)$ and infected tissue (d) of susceptible pineapple

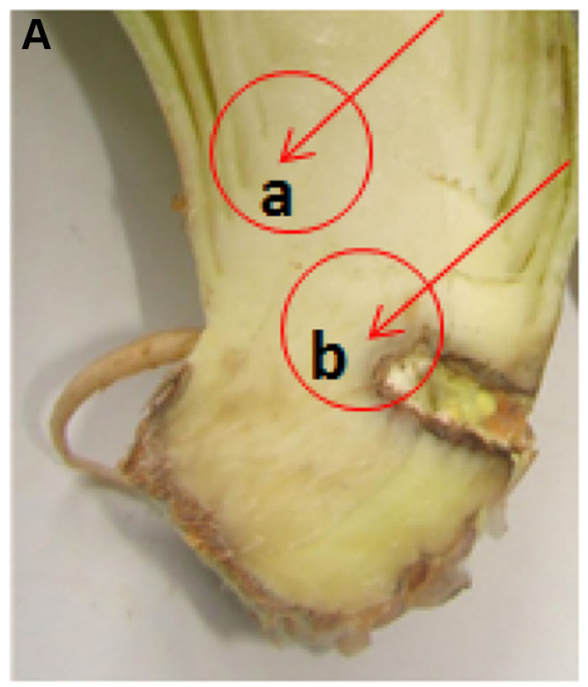

complex and subjected to phylogenetic analysis using maximum parsimony method.

\section{Macro- and Micro-Morphology}

Seven-day-old conidia of strain $F$. guttiforme E-480 on PDA were suspended in $500 \mu \mathrm{l}$ of $0.2 \%$ agar. The $F$. guttiforme E-480 monosporic isolate was transferred to plates of Spezieller Nährstoffarmer Agar (SNA, per liter: $0.2 \mathrm{~g}$ sucrose, $0.2 \mathrm{~g}$ glucose, $1.0 \mathrm{~g} \mathrm{KNO}_{3}, 1.0 \mathrm{~g} \mathrm{KH}_{2} \mathrm{PO}_{4}$, $0.5 \mathrm{~g} \mathrm{MgSO}_{4} \cdot 7 \mathrm{H}_{2} \mathrm{O}, 0.5 \mathrm{~g} \mathrm{NaCl}$, and $12 \mathrm{~g}$ agar) medium and incubated at $20{ }^{\circ} \mathrm{C}$ under intermittent light $(12 \mathrm{~h}$ under fluorescent plus near UV light) and dark period (12 h dark photoperiod) during 10 days. After incubation, the macroand micro-morphologic characteristics of the $F$. guttiforme E-480 colony was examined. Reproductive structures (conidia from the aerial mycelium, sporodochia, and phialides) were measured. Identification followed the taxonomic keys and guides available for Fusarium [10].

\section{Results}

The morphological identification of $F$. guttiforme E-480 was confirmed by molecular biology using tef- 1 and tub- 2 partial gene regions. The analysis of sequence data in GenBank database confirmed $F$. guttiforme identification for strain E-480. This strain was grouped with other $F$. guttiforme strains forming a single clade (65\% bootstrap) distinct from $F$. ananatum and other phylogenetic species of the Gibberella fujikuroi complex (Fig. 1).

After inoculation of $F$. guttiforme E-480 conidia into each resistant (Imperial cultivar, Fig. 2a) and susceptible (Pérola cultivar, Fig. 2b) pineapple side shot and incubation at $25{ }^{\circ} \mathrm{C}$, the tissue of the resistant pineapple did not change its integrity (Fig. 2a). In contrast, the tissue of the susceptible pineapple side steam started to become necrotic (Fig. 2b). Spectral analysis by MALDI-TOF on healthy tissue of resistant (Fig. 3a) and susceptible (Fig. 3d) cultivars presented a set of common mass peaks with the main highest ones centred at $5870 \mathrm{Da}$. These mass peaks were common to both pineapple cultivars and were not associated with fugal cellular material, but with pineapple tissue only.

The MALDI-TOF spectra from 2 to $20 \mathrm{kDa}$ obtained for pure colony of $F$. guttiforme E-480 (grown on the PDA plate) and for both the healthy tissue and the lesion border of resistant and susceptible cultivars are shown in Fig. 2a and $b$. Spectral details are given for both cases in the middle and bottom spectra in Fig. 3b and c (resistant cultivar) and in Fig. 3e and $\mathrm{f}$ (susceptible cultivar). Moreover, Fig. 3a and d (top spectra) shows the entire spectra for pure culture of strain $F$. guttiforme E-480.

Considering the comparison among these spectra, it can be possible to observe that any fungal mass peaks do not match with mass peaks of resistant pineapple tissues (Fig. 3a-c). This result corroborates that this fungal strain did not grow on the resistant pineapple side shot Imperial cultivar tissue. In contrast, the MALDI-TOF spectrum for pure culture of $F$. guttiforme E-480 (grown on the PDA plate, Fig. 3d, top spectrum) and spectrum obtained for the infected tissue of the susceptible pineapple (Fig. 3e and f, middle and bottom spectra) show noticeably the presence of fungal mass peaks in the pineapple tissue (c.f. peak at c.a. 4901 Da in Fig. 3e and f).

Also, when compared with the healthy tissue (Fig. 3d, bottom spectrum), it can also be observed a shift from 5870 to $5713 \mathrm{Da}$ in the molecular masses of the susceptible pineapple infected tissue (Fig. 3d, middle spectra). This can be due to the degradation capability of the susceptible 

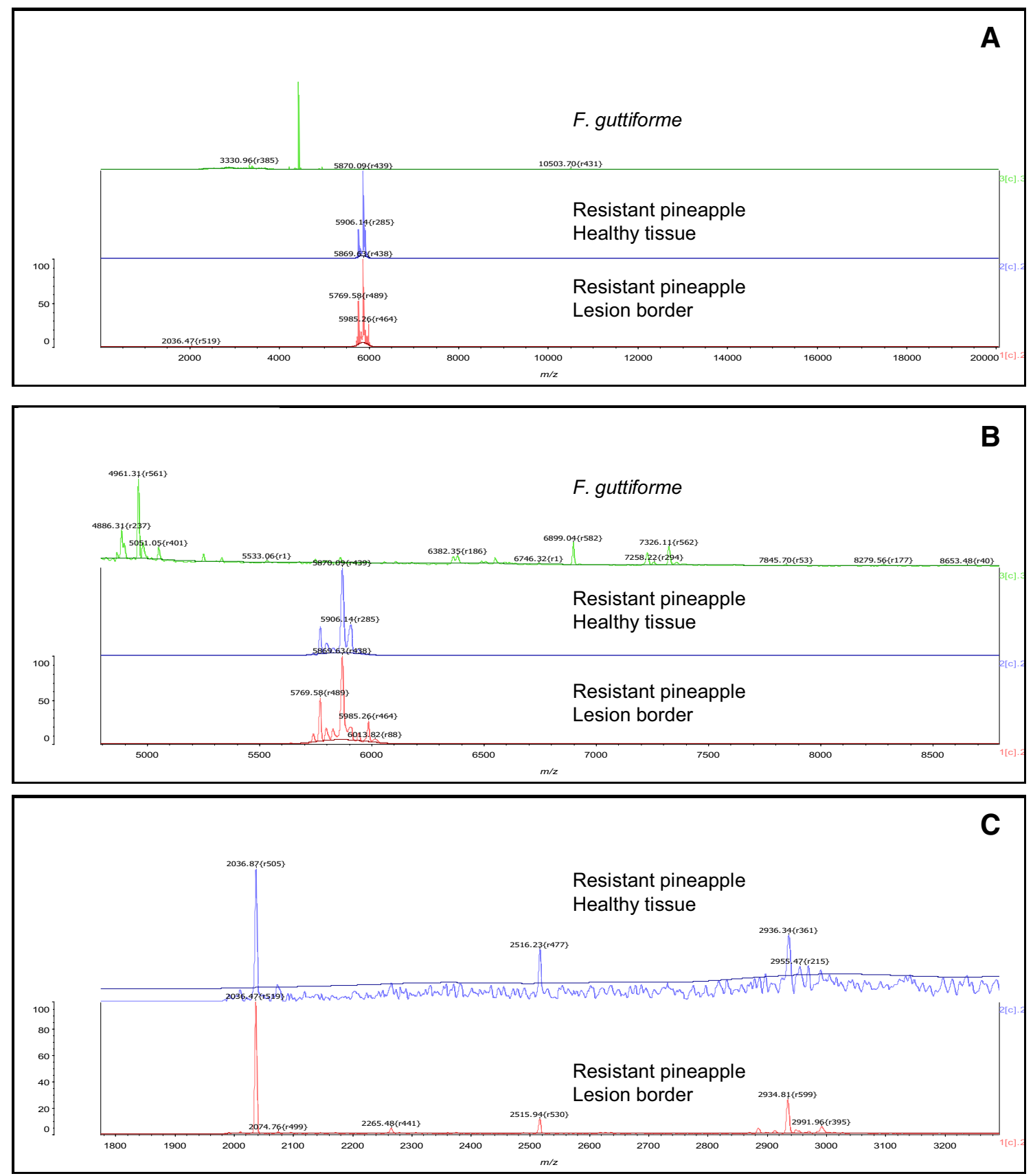

Fig. 3 MALDI-TOF MS spectrum of pineapple side stems inoculated with strain F. guttiforme E-480. On the left spectra (a-c) of resistant pineapple side stems, and on the right spectra (d-f) of susceptible pineapple side stems

pineapple cellular tissue by the fungus. In addition, it can be observed a set of biomarker peaks between 3100 and $3250 \mathrm{Da}$ that belong to the healthy tissue of susceptible pineapple side stem (Fig. 3f, bottom spectrum). After fungal infection, these mass peaks are not any more present on the spectrum (Fig. 3f, middle spectrum). It also gives indication of possible cellular degradation of the pineapple tissue by the fungus.

\section{Discussion}

Since the last decade, the mass spectrometry by MALDITOF technology has increasingly been applied to the identification of different microbial taxa [14, 22, 25]. However, its full potentialities in this field are still on its infancy. Moreover, with a microbial world still to be explored with $1 \%$ of microorganisms known, MALDI- 

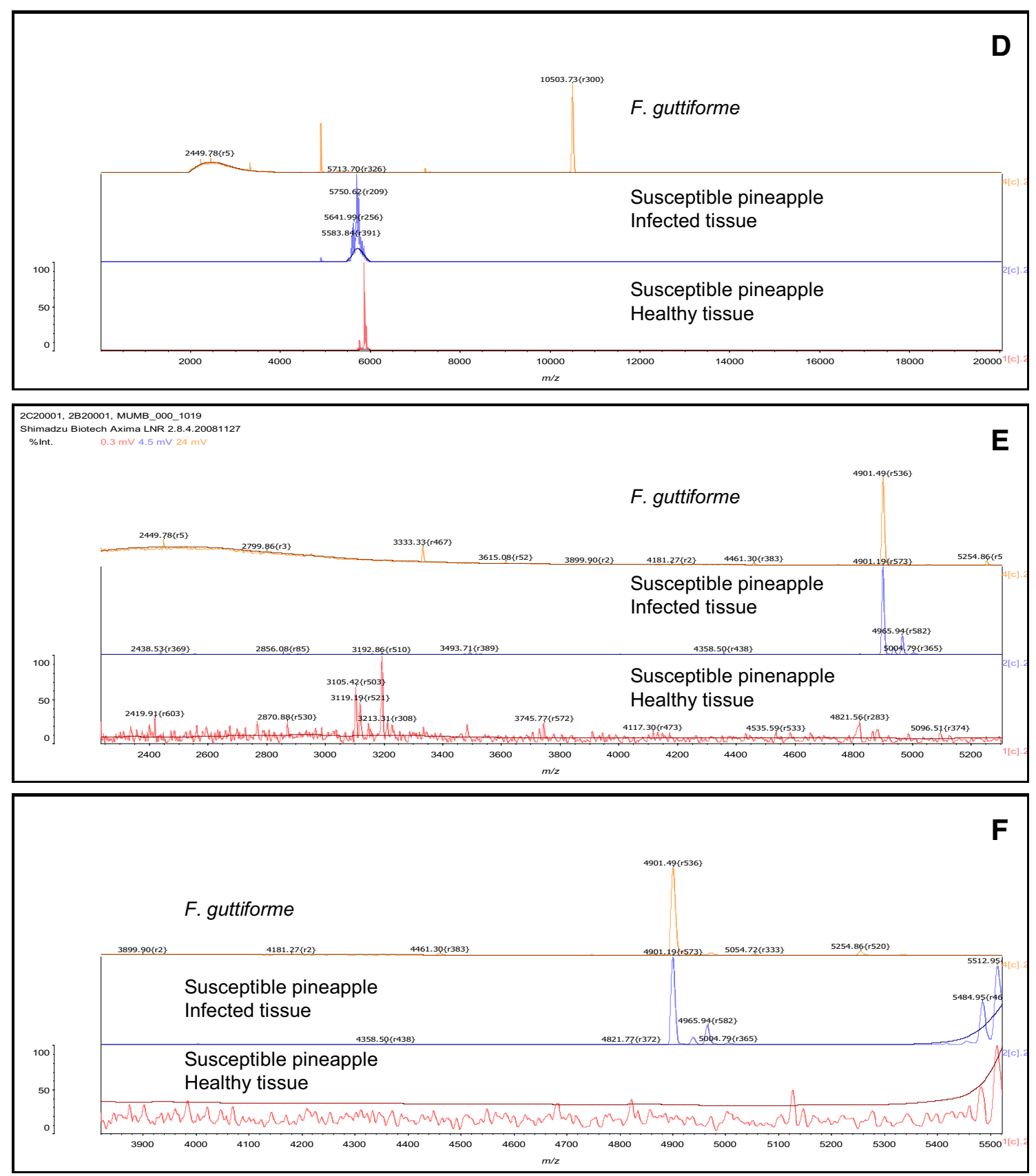

Fig. 3 continued

TOF has clear advantages on other microbial identification methodologies (e.g., physiological and molecular methods).

In the mycological field, this technique is already a wellrecognised approach for reliable fungal identification. Studies involving MALDI-TOF have been developed in the clinical, food, and environmental mycological areas [3, 11, $17,18,20,21]$. However, these publications available on literature are based on the fungal diagnosis after previous microbial isolation and growth in standardised conditions $[5,6,8,22]$.

In the present study, the specific mass peaks observed in the MALDI-TOF spectra are mainly attributed to the fungal ribosomal proteins. Ribosomal proteins have been described as excellent candidates for microbial identification, as they are universal within cellular life [17].

Previous analyses with fungal species reported that most ribosomal proteins are highly conserved, and some of these 
proteins are subject to slight variations at the strain level [20]. Therefore, variations in ribosomal protein genes have been proposed for classification and typing purposes in fungal species through MALDI-TOF MS [18]. The use of ribosomal protein mass analysis in a MALDI-TOF MS is herein evidenced as an interesting tool for classification of F. guttiforme into pineapple side steam.

Santos et al. [23] proposed a methodology for the detection of $F$. guttiforme in the pineapple side steam with concomitant identification of $T$. asperellum, which was acting as antagonist against $F$. guttiforme species. According to authors, the fungal growth conditions seemed less important than the intra-specific ribosomal proteins variation for each Fusarium strains. Furthermore, authors attested that $T$. asperellum was successfully identified when grown jointly with $F$. guttiforme on pineapple side shoots, and conclude that spectral differences based on different growth conditions depended on the genus or species analysed.

Ahmad et al. [1] have revised the MALDI-TOF potentiality as a rapid detection technique in plant pathology. In this review, authors proposed strategies for characterisation of plant-associated microorganisms. According to the authors, plant-associated microorganisms can be categorised into four broad categories: fungi, bacteria, nematodes, and viruses and virus-like organisms. Although in this review article authors have discussed bottlenecks and achievements in the application of MALDI-TOF MS in plant pathology, no previously experimental results on the specific subject were presented and discussed. Of course, there is scarce or even absent experimental data on this theme.

Beyond MALDI-TOF, some other analytical methodologies have been applied for the diagnosis of microorganisms infecting crops. In order to control the bayoud disease in date palm, caused by the fungus Fusarium oxysporum f. sp. albedinis (Phoenix dactylifera L.), Sedra and Lazrek [24] have presented a methodology based on the selection of resistant cultivars of date palm. The use of pathogen toxins in vitro selection was the approach used by these authors for rapid screening for date palm resistance to bayoud disease. Toxins evaluated could be used as indicative biomarkers of infection of susceptible date palm by bayoud disease.

Detection of toxins was based on HPLC analysis. In comparison with MALDI-TOF, chromatographic techniques such as HPLC can increase the cost analysis per sample and be time consuming when a fast answer is required. Furthermore, beyond sample preparation and consumables, limitation on detection of limited class of compounds is a remarkable differentiation between MALDI-TOF and HPLC.
Overall, MALDI-TOF-based fingerprinting approach has herein been demonstrated to be sensitive and accurate not only for the identification of pure fungal cultures, but also for the direct detection of $F$. guttiforme E-480 mass peaks on both susceptible and resistant pineapple side stems without any pre-treatment. According to the results obtained, the changing on molecular masses of infected susceptible pineapple tissue together with the possibility of fungal masses analysis into this pineapple tissue is a good indication for an early diagnosis of pineapple fusariosis.

In addition, through results obtained in the present study, it is possible to conclude that MALDI-TOF MS is an objective and fast analytical methodology for the early diagnosis of pineapple fusariosis. Moreover, MALDI-TOF MS is inexpensive in terms of labour and consumables when compared to other analytical techniques. As a matter of consequence, it is suitable for applications on agriculture field that have particular needs in high-throughput and fast answers.

\section{References}

1. Ahmad F, Babalola OO, Tak HI (2012) Potential of MALDI-TOF mass spectrometry as a rapid detection technique in plant pathology: identification of plant-associated microorganisms. Anal Bioanal Chem 404:1247-1255

2. De Respinis S, Vogel G, Benagli C, Tonolla M, Petrini O, Samuels GJ (2010) MALDI-TOF MS of Trichoderma: a model system for the identification of microfungi. Mycol Prog 9:79-100

3. Dias N, Santos C, Portela M, Lima N (2011) Toenail onychomycosis in a Portuguese geriatric population. Mycopathologia 172:55-61

4. Dong H, Kemptner J, Marchetti-Deschmann M, Kubicek CP, Allmaier G (2009) Development of a MALDI two-layer volume sample preparation technique for analysis of colored conidia spores of Fusarium by MALDI linear TOF mass spectrometry. Anal Bioanal Chem 395:1373-1383

5. Dong H, Marchetti-Deschmann M, Winkler W, Lohninger H, Allmaier G (2009) Intact cell/spore mass spectrometry of Fusarium macro conidia for fast isolate and species differentiation. In: Banoub J (ed) Detection of biological agents for the prevention of bioterrorism, NATO Science for Peace and Security Series - A: Chemistry and Biology. Springer, Dordrecht, pp 47-63

6. Ferreira L, Sánchez-Juanes F, Porras-Guerra I, García-García MI, García-Sánchez JE, González-Buitrago JM, Munõz-Bellido JL (2011) Microorganisms direct identification from blood culture by matrix assisted laser desorption/ionization time-of-flight mass spectrometry. Clin Microbiol Infec 17:546-551

7. Geiser DM, Jimenez-Gasco MM, Kang S, Makalowska I, Veeraraghavan N, Ward TJ, Zhang N, Kuldau GA, O'Donnell K (2004) Fusarium-ID v. 1.0: a DNA sequence database for identifying Fusarium. Eur J Plant Pathol 110:473-479

8. Kemptner J, Marchetti-Deschmann M, Kubicekb CP, Allmaier G (2009) Mixed volume sample preparation method for intact cell mass spectrometry of Fusarium spores. J Mass Spec 44: 1622-1624 
9. Kemptner J, Marchetti-Deschmann M, Mach R, Druzhinina IS, Kubicek CP, Allmaier G (2009) Evaluation of matrix-assisted laser desorption/ionization (MALDI) preparation techniques for surface characterization of intact Fusarium spores by MALDI linear time-of-flight mass spectrometry. Rapid Com Mass Spec 23:877-884

10. Leslie JF, Summerell BA, Bullock S (2006) The Fusarium laboratory manual. Blackwell Publishing Professional, South Africa, pp 57-60

11. Marchetti-Deschmann M, Winkler W, Dong H, Lohninger H, Kubicek CP, Allmaier G (2012) Using spores for Fusarium spp. Classification by MALDI-based intact cell/spore mass spectrometry. Food Technol Biotechnol 50:334-342

12. Marinach-Patrice C, Lethuillier A, Marly A, Brossas J-Y, Gene J, Symoens F, Datry A, Guarro J, Mazier D, Hennequin C (2009) Use of mass spectrometry to identify clinical Fusarium isolates. Clin Microbiol Infec 15:634-642

13. Marvin LF, Roberts MA, Fay LB (2003) Matrix assisted laser desorption/ionization time-of-flight mass spectrometry in clinical chemistry. Clin Chim Acta 337:11-21

14. Nicolau A, Sequeira L, Santos C, Mota M (2014) Matrix-assisted laser desorption/ionisation time-of-flight mass spectrometry (MALDI-TOF MS) applied to diatom identification: influence of culturing age. Aquat Biol 20:139-144

15. O’Donnell K, Kistler HC, Cigelnik E, Ploetz RD (1998) Multiple evolutionary origins of the fungus causing Panama disease of banana: concordant evidence from nuclear and mitochondrial gene genealogies. Proc Natl Acad Sci USA 95:2044-2049

16. Oliveira MME, Santos C, Sampaio P, Romeo O, Almeida-Paes R, Pais C, Lima N, Zancope-Oliveira RM (2015) Development and optimization of a new MALDI-TOF protocol for identification of the Sporothrix species complex. Res Microbiol 166:102-110

17. Passarini MRZ, Santos C, Lima N, Berlinck RGS, Sette LD (2013) Filamentous fungi from the Atlantic marine sponge Dragmacidon reticulatum. Arch Microbiol 195:99-111
18. Pereira L, Dias N, Santos C, Lima N (2014) The use of MALDITOF ICMS as an alternative tool for Trichophyton rubrum identification and typing. Enferm Infecc Microbiol Clin 32:11-17

19. Rahjoo V, Zad J, Javan-Nikkhah M, Mirzadi GA, Okhovvat SM, Bihamta MR, Razzaghian J, Klemsdal SS (2008) Morphological and molecular identification of Fusarium isolated from maize ears in Iran. J Plant Pathol 90:463-468

20. Rodrigues P, Santos C, Venâncio A, Lima N (2011) Species identification of Aspergillus section Flavi isolates from Portuguese almonds using phenotypic, including MALDI-TOF ICMS, and molecular approaches. J App Microbiol 111:877-892

21. Santos C, Lima N, Sampaio P, Pais C (2011) Matrix-assisted laser desorption/ionizationtime-of-flight intact cell mass spectrometry to detect emerging pathogenic Candida species. Diag Microbiol Infec Dis 71:304-308

22. Santos C, Paterson RMR, Venâncio A, Lima N (2010) Filamentous fungal characterisations by matrix-assisted laser desorption/ionisation time of flight mass spectrometry. J App Microbiol 108:375-385

23. Santos C, Ventura JA, Costa H, Fernandes PMB, Lima N (2015) MALDI-TOF MS to identify the pineapple pathogen Fusarium guttiforme and its antagonist Trichoderma asperellum on decayed pineapple. Trop Plant Pathol 40:227-232

24. Sedra MH, Lazrek BH (2011) Fusarium oxysporum f. sp. albedinis toxin characterization and use for selection of resistant date palm to bayoud disease. In: Jain SM, Al-Khayri JM, Johnson DV (eds) Date palm biotechnology. Springer, Dordrecht, pp 253-270

25. Shah HN, Gharbia SE (2010) Mass spectrometry for microbial proteomics. Wiley, Chichester, pp 255-270

26. Silva FC, Chalfoun SM, Batista LR, Santos C, Lima N (2015) Use of a polyphasic approach including MALDI-TOF MS for identification of Aspergillus section Flavi strains isolated from food commodities in Brazil. Ann Microbiol 65:2119-2129 